d patient information leaflets fulfil all the requirements for information on prescribed medication.

e Incapacitated patients who do not resist or question their treatment, require no special consideration or advocacy.

4. Regarding compliance:

a compliance may be facilitated by simplifying medication regimens

b a compliance aid is useful in all cases of poor compliance

c some medicines are not stable in compliance aids

$\mathrm{d}$ non-compliance is a common cause of treatment failure

e any tablets or capsules can be crushed and administered with a drink.

5. When incapacitated patients do not comply with medication:

a the Mental Health Act always applies b treatment plans must be critically reviewed and all attempts to give medication in the usual way made

c if persuasion fails, patients must be left untreated, regardless of the consequences

$\mathrm{d}$ as a last resort, medication may be administered covertly

e covert administration does not require multidisciplinary discussion or specific records to be made.

$\begin{array}{lllllllllll}\text { MCQ answers } & & & & & & \\ \text { 1 } & & \text { 2 } & & 3 & & 4 & & & 5 & \\ \text { a } & \text { T } & \text { a } & \text { F } & \text { a } & \text { F } & \text { a } & \text { T } & \text { a } & \text { F } \\ \text { b } & \text { T } & \text { b } & \text { T } & \text { b } & \text { T } & \text { b } & \text { F } & \text { b } & \text { T } \\ \text { c } & \text { T } & \text { c } & \text { F } & \text { c } & \text { F } & \text { c } & \text { T } & \text { c } & \text { F } \\ \text { d } & \text { F } & \text { d } & \text { T } & \text { d } & \text { F } & \text { d } & \text { T } & \text { d } & \text { T } \\ \text { e } & \text { F } & \text { e } & \text { T } & \text { e } & \text { F } & \text { e } & \text { F } & \text { e } & \text { F }\end{array}$

\title{
Commentary
}

\section{Rob Jones}

Treloar et al's comprehensive review (2001a, this issue) raises a number of issues of concern, especially in the ethical and legal arena, not only to old age psychiatry services but also far beyond (Lothian \& Philp, 2001), not least to carers.

But it is hard to keep pace in this fast-moving world. While Treloar et al's review has been in press, Doody et al (2001) have published an evidence-based review on the management of dementia. But in the very same journal Hogan \& McKeith (2001) noted that that work - resulting from the screening of 5956 articles, with 1054 reviewed in detail - was a "labor of Sisyphus - the moment it was completed it was outdated". In fact, Treloar et al quote evidence more recent than that in Doody et al, but they have reached print after Doody et al's authoritative conclusion that "Class I evidence supports the use of both traditional and atypical antipsychotics in the treatment of agitation and psychosis in dementia, and atypical agents seem to be better tolerated" and that such an approach should be used "where environmental manipulation fails". But, as Hogan \& McKeith point out:

\footnotetext{
“companies and researchers are investing heavily in dementia clinical trials, attempting for example to find the precise symptom targets for new antipsychotic agents and the role of cholinesterase inhibitors in very early and late stage AD."
}

Certainly, we do know (Thacker \& Jones, 1997; Challis et al, 2000) that the recently withdrawn

Rob Jones is Head of the Section of Old Age Psychiatry at Nottingham Medical School (A Floor, South Block, QMC, Nottingham NG7 2UH). His interests include the psychiatric needs of those in nursing/residential care and ethical and legal issues in old age psychiatry. 
thioridazine has been far and away the most popular antipsychotic for use in nursing/residential home patients, and must mostly have been given to people with dementia, the great majority of such residents (Macdonald, 1998). What is happening to these patients now? Are they just as well or even better without their thioridazine? Or have many been loaded up with other neuroleptics, or even with other medication such as trazodone, benzodiazepines or anticonvulsants? It would be ironic and unfortunate if thioridazine ended up being replaced by similarly poorly monitored and poorly evidencebased alternatives. Research is greatly needed here to discover what beneficial or other changes have occurred with these patients - and to find better ways of managing their problems, not least nonpharmacologically.

With ethical and legal issues, authors might hope that matters may change more slowly. However, legal issues have moved on since Treloar et al laid down their pens.

Treloar et al (2001b) have previously well discussed the ethical issues that arise when considering medication given covertly to a person with dementia who is mentally incapable. Benefit may be thought likely, but the individual cannot take part competently in discussion and may frequently, for whatever reasons, resist medication. Important points here are equity and reciprocity.

Individuals with dementia should be able to benefit from a treatment likely to improve quality of life. The opportunity should not be denied simply because the present pattern of their illness, or its individualistic presentation, is associated with uncomprehending resisting behaviour. Clearly, though, administration of any such treatment needs to be within the bounds of ethical good practice for this difficult situation and within relevant mental health and other law, with open practice available for audit and monitoring. But, the doctor's duty of care presses the need to seek ways to deliver the best appropriate care despite such practical difficulties or legal barriers - and to press for proper change in the law if this is an impediment to ethical practice (Jones, 2001).

Reciprocity, which the Richardson Report (Department of Health, 1999) discusses in the context of risk to patient autonomy, is relevant when incapable people with dementia need antipsychotic treatment in their best interests. These vulnerable people deserve to benefit from the best available treatment even if more expensive - not just something cheap that will do. Mounting evidence that, overall, atypicals may be more beneficial here must be kept in view (as in Doody et al, 2001).

Otherwise, relevant also to equity and reciprocity, Treloar et al mentioned the problem with varying availability of anti-dementia drugs. The response of funders in the UK has definitely been "patchy" (Benbow et al, 1999). But the publication of the National Service Framework for Older People (Department of Health, 2001), with its anti-ageist agenda, and the earlier NHS Plan (Department of Health, 2000a), linked to the NICE guidelines, has been highlighted by the Secretary of State as ensuring equity of access. Failure of delivery here will be highly noticeable.

Treloar et al's (2001a) mention of discussion with a pharmacist is supported by Furniss et al (1998), who have noted the benefits to nursing home residents of a pharmacist's review; those with mental incapacity are, arguably, most likely to benefit from such a service, being least able themselves to raise concerns and problems.

Since Treloar et al submitted their review, there have been further developments in the legal arena, at least from the point of view of proposals for mental health reform (Department of Health, 2000b). As part of the proposals for reforming the Mental Health Act 1983 (for England and Wales), the Government has announced the intention to introduce a separate framework of safeguards for mentally incapable people. The proposed new Commission for Mental Health would have them within its remit and there would be a right to apply to new Mental Health Tribunals. The aim stated is to protect the interests of those unable fully to express their wishes. It is said that the focus is intended to be on the quality of care and treatment the patient receives, with particular emphasis on ensuring that it is in an appropriate setting and without unnecessary coercion or deprivation of liberty.

What is surprising in the proposal is that only those being cared for by specialist mental health services will be subject to the new framework. Clearly, the great majority of people with mental incapacity are not directly cared for by such services, that is, the great majority in nursing/residential care homes and most of the potentially incapable among older people occupying $75 \%$ of hospital beds.

The new framework seems likely to require the extended form of the Care Programme Approach with this group and a good bit of bureaucratic procedure to be laid down. Essentially, the clinical supervisor must draw up a care and treatment plan with such a patient and certify that: it is in the patient's best interest; the patient is not actively resisting; and the patient does not pose a significant risk of serious harm to other people. The clinical supervisor will also have to arrange for a second opinion doctor used by the Tribunal to examine the patient and to discuss the plan, suggesting changes if appropriate. The patient's carers and close relatives are also to be consulted and a social care 
representative will nominate a person to represent the patient. The implication of the proposals, perhaps unfortunately, is that it is particularly those 'in the clutches' of specialist services who need such safeguards. In practice, as Treloar et al have noted, it is very much those incapable people who are not posing problems, i.e. those who assent, who are probably the most vulnerable. Hopefully, specialist mental health services will add to the expertise and quality of care of those lacking mental capacity in care homes. But the considerable bureaucratic burden associated with the procedure makes it likely that, unfortunately, they will retreat and limit their involvement.

While the protective intention of these proposals is clearly good, without significant expansion in consultant numbers a detrimental effect on the quality of patient care seems likely, at least in the medium term. The approach seems strikingly at odds with the rather more relaxed dependence on good practice of the Lord Chancellor's proposals.

The White Paper (Department of Health, 2000b) sees this approach as applying potentially to:

"any patient with long-term mental incapacity who is assessed as needing long-term care and/or treatment for serious mental disorder from specialist mental health services in his or her best interests."

It will apply to patients in "hospital, or in a care home" but not to a patient who is "living independently" at home. Many definitions and questions are begged here and will need resolution. And any such legislation risks being significantly uncoordinated with approaches and procedures in the proposed Incapacity Act. There is much for us to consider here, a "paper blizzard" in prospect (Burton, 2001), and a great deal for us to do in terms of advising on what sensible and practical procedures should be applied to meet these real problems (Jones, 2001).

\section{References}

Benbow, S., Jones, R. \& Jolley, D. (1999) Short rations. Health Services Journal, 26-27.

Burton, S. (2001) Mental health reforms - have you seen what's coming? Old Age Psychiatrist, 22, 4-5.

Challis, D., Mozely, C. G., Sutcliffe, C., et al (2000) Dependency in older people recently admitted to care homes. Age and Ageing, 29, 255-260.

Department of Health (1999) Richardson Report. Review of the Expert Committee: Review of the Mental Health Act 1983. Cm4480. London: Stationery Office.

- (2000a) The NHS Plan. A Plan for Investment. A Plan for reform. London: Stationery Office.

- $(2000 b)$ Reforming the Mental Health Act. Parts I-II. Cm5016. London: Stationery Office.

- (2001) National Servcie Framework for Older People. London: Stationery Office.

Doody, R. S., Stevens, J. C., Beck, C., et al (2001) Practice parameter: management of dementia (an evidence-based review): report of the Quality Standards Sub-Committee of the American Academy of Neurology. Neurology, 56, 1154-1166.

Furniss, L., Craig, S. K. \& Burns, A. (1998) Medication use in nursing homes for the elderly. International Journal of Geriatric Psychiatry, 13, 433-439.

Hogan, D. B. \& McKeith, I. G. (2001) Of MCI and dementia: improving diagnosis and treatment (editorial). Neurology, 56, 1131-1132.

Jones, R. G. (2001) Ethical and legal issues in the care of people with dementia. Reviews in Clinical Gerontology, in press.

Lothian, K. \& Philp, I. (2001) Care of older people: Maintaining the dignity and autonomy of older people in the healthcare setting. British Medical Journal, 322, $668-670$

Macdonald, A. J. D. (1998) Mental Health in Old Age in ABC of Mental Health (ed. T. Davies \& T. K. J. Craig). London: BMJ Books.

Thacker, S. \& Jones, R. (1997) Neuroleptic prescribing to the community elderly in Nottingham. International Journal of Geriatric Psychiatry, 46, 77-82.

Treloar, A., Beck, S. \& Paton, C. (2001a) Administering medicines to patients with dementia and other organic cognitive syndromes. Advances in Psychiatric Treatment, 7, 444-450.

—, Philpot, M. \& Beats, B. (2001b) Concealing medication in patients food. Lancet, 357, 62-64. 